\title{
Distinct neuropsychological correlates of cognitive, behavioral, and affective apathy sub-domains in acquired brain injury
}

\author{
Progress Njomboro ${ }^{1}$ * and Shoumitro Deb ${ }^{2}$ \\ 1 Department of Psychology, University of Cape Town, Cape Town, South Africa \\ ${ }^{2}$ Division of Brain Sciences, Department of Medicine, Imperial College London, London, UK
}

\section{Edited by:}

Sanjay Kumar, University of Oxford, UK

\section{Reviewed by:}

Tessa Hart, Moss Rehabilitation

Research Institute, USA

Antonino F. Germano, University of

Messina, Italy

Tina Malhotra, Avon and Wiltshire

Mental Health Partnership NHS Trust,

UK

*Correspondence:

Progress Njomboro, Department of Psychology, University of Cape Town, Private Bag Rondebosch, Cape Town 7701, South Africa

e-mail:progress.njomboro@uct.ac.za
Apathy has a high prevalence and a significant contribution to treatment and rehabilitation outcomes in acquired brain damage. Research on the disorder's neuropsychological correlates has produced mixed results. While the mixed picture may be due to the use of varied assessment tools on different patient populations, it is also the case that most studies treat apathy as a unitary syndrome. This is despite the evidence that apathy is a multifaceted and multidimensional syndrome. This study investigates the neuropsychological correlates of apathy in 49 patients with acquired brain damage. It further fractionates apathy symptoms into affective, cognitive, and behavioral sub-domains and investigates their individual relations with standard measures of affective, cognitive, and behavioral functioning. Global apathy scores were not related to any of these measures. Affective apathy was associated with emotion perception deficits, and cognitive apathy was associated with executive deficits on the Brixton test. These results demonstrate that treating apathy as a single entity may hide important correlates to apathy symptoms that become visible when the disorder is fractionated into its sub-domains. The study highlights the research and clinical importance of treating apathy as a multidimensional syndrome.

Keywords: apathy, affective, cognitive, behavioral, depression

\section{INTRODUCTION}

Since Marin's seminal work on apathy in the early 1990s, there has been a tremendous growth in the amount of research on the disorder and a general appreciation of its clinical relevance. It is now widely agreed that apathy constitutes a quantitative reduction in self-generated voluntary and purposeful acts, and that this reduction in activity reflects dysfunctions in affective, cognitive, and behavioral processes relating to the planning, execution, and control of goal directed behavior (1-5). Prevalence studies show that apathy is the most common long-term clinical feature following brain injury $(3,6)$. A meta-analytical study covering 19 studies with a total of 2221 patients by Caeiro et al. (7) found that the frequency of apathy across studies ranged between 15.2 and $71.1 \%$ [see also Ref. $(8,9)$ for similar findings]. Patients with apathy present with more negative rehabilitation outcomes in terms of poor recovery $(6,10,11)$, problems in daily functioning $(12)$, lack of post-injury social reintegration (13), loss of social autonomy (14), financial and vocational loss (8), significant neuropsychological dysfunction (2, 7, 12,15-18), and caregiver distress (19). Yet, apathy is still a neglected neuropsychiatric syndrome in clinical practice, with no known standard treatment approaches and remains largely excluded from major psychiatric disease classification systems.

Apathy's position in relation to other neuropsychiatric conditions is also less clear, particularly its relationship to negative symptoms, dysexecutive syndrome, or affective illness (20-22). Studies investigating the neural substrates of apathy implicate a diverse range of cortical and sub-cortical brain areas (23-25).
This lack of clarity probably reflects the lack of consensus on the definition of apathy, or the use of different clinical measures and neuropsychological tests and/or different neuropsychiatric patients across studies. It is, however, important to also note that the majority of studies treat apathy as a unitary disorder, while it is actually a multifaceted syndrome with distinct affective, cognitive, and behavioral sub-domains $(2,5,20)$. The prominence of any one of these sub-domains on the clinical profile depends on the specific underlying neural involvement in neuropsychiatric illness (23-26). For instance, Sultzer et al. (25) found that: (1) affective apathy symptoms are associated with low metabolism in left medial temporal, right anterior temporal, and left inferior frontal cortex, (2) cognitive apathy symptoms are associated with low metabolic activity in bilateral medial thalamus, bilateral anterior cingulate, and left insula, and (3) behavioral apathy symptoms are associated with low activity in bilateral insula. Chow et al. (24) also point out that affective symptoms are linked to damage in emotion related sub-cortical circuits involving the limbic structures, while cognitive symptoms are associated with frontal lobe dysfunction [see also Ref. $(23,26,27)]$.

This study investigates the correlates of apathy symptoms while controlling for the contribution of individual apathy sub-domains to neurocognitive functioning. Isolating these sub-domains and investigating their individual relations to neuropsychological performance has both theoretical validity and empirical utility. This approach takes into account the multifaceted nature of apathy symptoms and acknowledges the importance of treating these 
domains separately when investigating the neuropsychological profiles that may accompany them. Furthermore, imaging studies with neurologically intact participants indicate that the processes that are disabled in apathy, such as those involved in self-initiation, emotional expression and feeling, and volition, are neurally distinct $(24,25)$. Fractionating apathy symptoms into affective, cognitive, and behavioral sub-domains may help us better investigate these associated neurobehavioral correlates. Previous studies have also tended to use homogeneous patient samples, making it difficult to isolate apathy correlates from those related to the specific disease process. This study includes a heterogonous sample of brain damaged patients in order to dilute the influence of disease-specific effects and strengthen the relations between apathy symptoms and the study variables.

The main aim of this study is to identify the neuropsychological correlates of the affective, cognitive, and behavioral sub-domains of apathy. The speculation is that each of these three sub-domains has distinct correlates. Specifically, three hypotheses are made. Hypothesis (1): affective apathy symptoms predict poor outcomes on affective measures in terms of more depressive symptoms on the Beck depression inventory (BDI) and also predict poor perception of basic emotions on the Emotion Hexagon test; Hypothesis (2): cognitive apathy symptoms predict poor performance on a cognitive test of executive function (the Brixton test); and Hypothesis (3): behavioral apathy symptoms predict poor goal directed behavior on the Iowa gambling task (IGT).

\section{MATERIALS AND METHODS \\ PARTICIPANTS}

Participants for this study were recruited from clinics and rehabilitation centers within the United Kingdom's city of Birmingham. In total, 49 patients with acquired brain damage were recruited. All the patients were at least 6 months post-injury and were screened through the Birmingham Cognitive Screen (28) to establish suitability for participation in the study (see Table 1 for the cause of injury and patients' demographic characteristics).

Imaging results and lesion data were obtained from patient files and were available in 46 patients (see Table 2). All participants gave informed written consent, and the ethics approval for the study was granted by the Birmingham and Solihull Research Ethics Committee.

\section{MEASURES}

\section{ASSESSMENT OF APATHY}

The informant rated Apathy Evaluation Scale (AES-I) (20) was used to assess apathy symptoms. The AES is the most widely used scale for evaluating apathy symptoms and has demonstrated good psychometric properties (21). The 18 items on the scale assess behavioral apathy symptoms (e.g., He/she spends time doing things that interest her/him), emotional apathy symptoms (e.g., When something good happens, he/she gets excited), and cognitive apathy symptoms (e.g., S/he is interested in things). Each item is rated on a scale of 1 (Not at all) to 4 (A lot).

\section{ASSESSMENT OF AFFECTIVE FUNCTIONING \\ Depression}

The level and presence of depressive symptoms was evaluated using the BDI II (29).
Table 1 | Patients' demographic characteristics and cause of brain injury.

\begin{tabular}{|c|c|c|c|}
\hline Etiology & $N$ & $\begin{array}{l}\text { Sex } \\
M=\text { male; } \\
F=\text { female }\end{array}$ & $\begin{array}{l}\text { Age } \\
\text { Mean and SD }\end{array}$ \\
\hline Cerebrovascular accident (CVA) & 24 & $M=15 ; F=9$ & $54.44(12.29)$ \\
\hline Head injury & 14 & $M=11 ; F=3$ & $48.25(15.27)$ \\
\hline Anoxia & 5 & $M=5 ; F=0$ & $49.80(11.05)$ \\
\hline Herpes simplex encephalitis (HSE) & 6 & $M=5 ; F=1$ & $42.50(8.60)$ \\
\hline Total & 49 & $M=36 ; F=13$ & $48.75(11.80)$ \\
\hline
\end{tabular}

Table 2 | Lesion location for study participants.

\begin{tabular}{lc}
\hline Lesion location & Number of patients \\
\hline Left parietal & 5 \\
Right parietal & 4 \\
Bilateral parietal & 1 \\
Left fronto-temporal & 7 \\
Right fronto-temporal & 7 \\
Bilateral fronto-temporal & 22 \\
Total $(N)$ & 46 \\
\hline
\end{tabular}

\section{Emotion perception}

The Emotion Hexagon test from the facial expressions of emotions stimuli and tests (FEEST) CD-ROM (30) was used to assess the recognition of facial expressions of emotion. The test assesses recognition of the six basic emotional categories of anger, disgust, fear, happiness, sadness, and surprise. The pictures of faces on the test are computer-manipulated and morphed such that each emotion is presented in graded levels of difficulty making the emotions relatively difficult to recognize. For that reason, the Hexagon test is a more valid measure of emotion perception because in real-life emotions are seldom expressed as a single pure emotion, but as complex combinations of mixed emotions. The test is made up of a total of 120 trials split into four blocks. Participants respond by using a mouse to click on one of the six emotion words (i.e., Anger, Disgust, Happiness, Sadness, Surprise, and Fear) presented at the bottom of a computer screen together with each emotional face; see Young et al. (30) for a full description of the test.

\section{ASSESSMENT OF COGNITIVE FUNCTIONING The Brixton test}

The Brixton Spatial Anticipation test (31) provided a measure of executive cognitive control. This test was chosen because of its limited semantic loading, and its sensitivity to deficits in a number of executive processes, including set shifting and rule or feedback use (32). The test consists of a series of pages in a booklet. Each page has the same basic design on it made up of a set of 10 circles in 2 rows. One of the circles among these 10 circles is colored blue, and the participants' task is to infer patterns in the sequence of positions of the blue circle and predict its position on subsequent pages. 


\section{ASSESSMENT OF BEHAVIORAL FUNCTIONING lowa gambling task}

The IGT assesses motivational decision making and performance on this task is thought to analog real-life goal directed behavior (33). The task requires participants to choose cards from four decks labeled A-D containing 40 cards each. Participants win and lose money on all the decks, but decks $\mathrm{A}$ and $\mathrm{B}$ give higher wins but even higher losses while decks $\mathrm{C}$ and $\mathrm{D}$ give relatively lower wins and similarly lower losses. Picking more cards from decks $\mathrm{A}$ and $\mathrm{B}$ gives a net loss while picking from decks $\mathrm{C}$ and $\mathrm{D}$ results in a net gain. Neurologically intact participants tend to avoid decks $A$ and $\mathrm{B}$ and pick more from decks $\mathrm{C}$ and $\mathrm{D}$ as the game progresses (33). Successful performance on the task is reflected by the number of cards picked from decks $\mathrm{C}$ and D. For each participant, the IGT score was the number of cards selected from these two decks.

\section{DATA ANALYSIS}

Initially, a Pearson correlation analysis was performed to investigate the relationship between global apathy (total AES-I score) and performance on the tests. Further multiple regression analyses were performed to investigate the influence of each of the three sub-domains of apathy (i.e., affective apathy, cognitive apathy, and behavioral apathy) on test performance. The total sub-domain score was obtained by summing up scores on all the AES-I items under that domain. A series of multiple linear regression analyses were then performed with the sub-domain scores treated as predictors of performance on the individual tests. The data analysis was done using SPSS Version 21 software (IBM, Armonk, NY, USA). All the data were tested for violations of the assumptions of normality, linearity, and homoscedasticity.

\section{RESULTS}

\section{NEUROPSYCHOLOGICAL CORRELATES OF GLOBAL APATHY}

Global apathy was not significantly related to any of the test measures. These results are shown in the correlation matrix in Table 3 below.

Hierarchical regression analyses were then performed to examine the individual contribution of affective, cognitive, and behavioral apathy sub-domains to performance on the individual neuropsychological tests. The results for each sub-domain are presented in the following sections below.

\section{AFFECTIVE APATHY AND DEPRESSIVE SYMPTOMS}

Hypothesis 1 suggested that affective apathy symptoms would be positively correlated to depressive symptoms. For this reason, affective apathy scores were entered in the first step of the regression model with depressive symptoms scores, and then cognitive and behavioral apathy scores were entered in the second step. Affective apathy symptoms were not a significant predictor of depressive symptoms in the first step of the model. Controlling for the influence of cognitive and behavioral apathy symptoms in the second step of the regression model also produces non-significant effects. These results are shown in Table 4.

\section{AFFECTIVE APATHY AND EMOTION PERCEPTION}

It had also been suggested in Hypothesis 1 that affective apathy symptoms would be associated with poor emotion recognition on
Table 3 | Correlations between global apathy and tests scores

\begin{tabular}{llllll}
\hline & & Hexagon & IGT & Brixton & AES-I \\
\hline IGT & Coefficient & 0.06 & & & \\
& Sig. & 0.63 & & & \\
\multirow{2}{*}{ Brixton } & Coefficient & 0.08 & 0.17 & & \\
& Sig. & 0.56 & 0.37 & & \\
\multirow{2}{*}{ AES-I } & Coefficient & 0.07 & 0.30 & 0.17 & \\
& Sig. & 0.67 & 0.11 & 0.29 & 0.06 \\
BDI & Coefficient & 0.18 & 0.01 & 0.10 & 0.70 \\
& Sig. & 0.23 & 0.99 & 0.50 & \\
\hline
\end{tabular}

Table 4 |The relationship between apathy domains and depressive symptoms

\begin{tabular}{lrrrr}
\hline & $\boldsymbol{B}$ & SE $\boldsymbol{B}$ & $\boldsymbol{\beta}$ & $\boldsymbol{p}$ \\
\hline $\begin{array}{l}\text { Step 1 } \\
\quad 14.48\end{array}$ & 4.70 & & \\
$\quad$ Constant & -0.04 & 0.94 & -0.01 & 0.99 \\
$\quad$ Affective apathy & & & & \\
Step 2 & 11.39 & 6.99 & & 0.69 \\
$\quad$ Constant & 0.58 & 1.45 & 0.09 & 0.38 \\
Affective apathy & -0.41 & 0.46 & -0.25 & 0.38 \\
$\quad$ Cognitive apathy & 0.70 & 0.79 & 0.19 & \\
Behavioral apathy & & & & \\
\hline
\end{tabular}

$R^{2}=0$ for step $1 ; \Delta R^{2}=0.02$ for step 2 (ps > 0.05).

the Emotion Hexagon test. Affective apathy scores were entered in the first step of the model together with the Hexagon test scores, followed by scores on cognitive and behavioral apathy symptoms in the second step. The influence of affective apathy symptoms on emotion perception was not significant in the first step of the model but was significant in step 2 after factoring in cognitive and behavioral symptoms. These results are shown in Table 5.

\section{COGNITIVE APATHY AND EXECUTIVE FUNCTION}

In Hypothesis 2, it has been predicted that higher cognitive apathy symptoms would be associated with poorer executive function performance on the Brixton test. Cognitive apathy scores were entered in the first step of the regression model together with Brixton scores, followed by affective and behavioral apathy scores in the second step. The contribution of cognitive apathy in the first step of the regression model neared significance $(p=0.06)$, suggesting that cognitive apathy symptoms are related to poor Brixton test performance. There were no significant predictors of executive function impairment on the Brixton test in the second step of the regression analysis (see Table $\mathbf{6}$ ).

\section{BEHAVIORAL APATHY AND MOTIVATIONAL DECISION MAKING}

Hypothesis 3 speculated that behavioral apathy scores would predict poor performance on the IGT, in line with the conceptualization of this task as an analog to real-life goal directed behavior. Behavioral apathy scores were entered in the first step of the regression analysis together with IGT scores, and then followed by cognitive and affective apathy scores in the second step. None 
Table 5 | Apathy and emotion recognition on the Emotion Hexagon test.

\begin{tabular}{lrrrr}
\hline & $\boldsymbol{B}$ & SE $\boldsymbol{B}$ & $\boldsymbol{\beta}$ & $\boldsymbol{p}$ \\
\hline Step 1 & & & & \\
$\quad$ Constant & 92.33 & 8.67 & & \\
$\quad$ Affective apathy & -2.42 & 1.73 & -0.20 & 0.17 \\
Step 2 & & & & \\
$\quad$ Constant & 80.00 & 12.55 & & \\
Affective apathy & -5.85 & 2.60 & -0.48 & $0.03^{*}$ \\
Cognitive apathy & 0.92 & 0.83 & 0.29 & 0.27 \\
$\quad$ Behavioral apathy & 0.85 & 1.41 & 0.12 & 0.55 \\
\hline
\end{tabular}

$R^{2}=0.04$ for step $1 ; \Delta R^{2}=0.07$ for step $2(p s>0.05)$.

${ }^{*} p<0.05$.

Table 6 | Apathy domains and the Brixton test

\begin{tabular}{lrrrr}
\hline & $\boldsymbol{B}$ & SE $\boldsymbol{B}$ & $\boldsymbol{\beta}$ & $\boldsymbol{p}$ \\
\hline $\begin{array}{l}\text { Step 1 } \\
\quad\end{array}$ & & & & \\
$\quad$ Constant & 18.89 & 3.51 & & \\
$\quad$ Cognitive apathy & 0.31 & 0.17 & 0.26 & 0.06 \\
$\begin{array}{l}\text { Step 2 } \\
\quad \text { Constant }\end{array}$ & 21.03 & 4.85 & & \\
$\quad$ Cognitive apathy & 0.35 & 0.32 & 0.29 & 0.28 \\
$\quad$ Affective apathy & 0.50 & 1.00 & 0.11 & 0.62 \\
$\quad$ Behavioral apathy & -0.45 & 0.54 & -0.17 & 0.42 \\
\hline
\end{tabular}

$R^{2}=0.07$ for step $1 ; \Delta R^{2}=0.02$ for $\operatorname{step} 2(p s=0.06) ; p=0.06$.

Table 7 | Apathy domains and the lowa gambling task.

\begin{tabular}{lrrrr}
\hline & $\boldsymbol{B}$ & SE $\boldsymbol{B}$ & $\boldsymbol{\beta}$ & $\boldsymbol{p}$ \\
\hline Step 1 & & & & \\
$\quad$ Constant & 49.38 & 14.27 & & \\
$\quad$ Behavioral apathy & -0.37 & 1.14 & -0.06 & 0.75 \\
Step 2 & & & & \\
$\quad$ Constant & 54.36 & 13.03 & & \\
$\quad$ Behavioral apathy & 2.23 & 1.46 & 0.38 & 0.14 \\
Cognitive apathy & -0.90 & 0.87 & -0.34 & 0.31 \\
Affective apathy & -3.97 & 2.70 & -0.39 & 0.15 \\
\hline
\end{tabular}

$R^{2}=0.01$ for step $1 ; \Delta R^{2}=0.27$ for step 2 (ps $>0.05$ ).

of the three apathy sub-domains was a significant predictor of performance on the IGT. The results from the regression model are shown in Table 7.

\section{DISCUSSION}

This study examined the predictive value of apathy symptoms on performance on a set of affective, cognitive, and behavioral neuropsychological tests. We found that cognitive apathy symptoms were associated with more errors on the Brixton test. This result was of borderline significance $(p=0.06)$. Affective apathy symptoms were not associated with poor emotion recognition on the Emotion Hexagon test, although adding cognitive and behavioral symptoms in the second part of the regression model showed significant interaction effects of these apathy sub-domains on emotion recognition. Affective apathy symptoms were not significant predictors of depressive symptoms on the BDI. Also, behavioral apathy symptoms were not significant predictors of performance on the IGT as had been expected. These results, particularly on the relation between cognitive apathy symptoms and executive function, and also on the relationship between the three apathy sub-domains and emotion recognition are interesting considering that our initial correlation analyses investigating these relationships using global apathy scores yielded non-significant relations. Overall, these results suggest a differential influence of the three dimensions of apathy symptoms on neuropsychological performance. The following sections discuss these results in more detail.

\section{CORRELATES OF AFFECTIVE APATHY Depression}

Depressive symptoms were not significantly correlated to either global apathy or to the affective sub-symptoms of apathy. Other studies have reported similar findings [e.g., Ref. (34-37)]. These results support the view that apathy is a distinct neuropsychiatric syndrome separable from depression (38). There is also evidence that apathy is not a clinical criterion of depression, even though some depression scales treat it as one (21). Taken in this context, the lack of a significant association between affective apathy symptoms and depressive symptoms is unremarkable.

\section{Emotion recognition}

The unique contribution of affective apathy symptoms to emotion recognition deficits was not significant [although adding cognitive and behavioral apathy symptoms to the regression model produced significant effects $(p=0.03)]$. Other studies with different clinical samples have reported poor emotion recognition in patients with apathy. For example, Martínez-Corral et al. (39) found that Parkinson's disease patients with apathy exhibited selective deficits in facial emotion recognition, with more specific deficits in the recognition of fear, anger, and sadness, while non-apathetic patients recognized facial emotions as accurately as healthy controls [however, see Ref. (40) for a different set of results]. Drapier et al. (41) suggest that apathy and emotion recognition share the same functional circuit involving the sub-thalamic nucleus (STN).

\section{CORRELATES OF COGNITIVE APATHY}

Higher cognitive apathy symptoms predicted more executive function deficits on the Brixton test. Numerous studies have also linked apathy to executive dysfunction (16,42-44). Levy and Dubois (17) have termed the cognitive sub-syndrome of apathy "cognitive inertia," in which there is a reduction in goal directed behavior due to impairments in the higher order functions responsible for the cognitive control of activity. It might be the case that an apathetic state with predominantly more cognitive apathy symptoms would manifest as a dysexecutive syndrome.

\section{CORRELATES OF BEHAVIORAL APATHY}

Behavioral apathy scores were not significant predictors of IGT performance in this study. Our hypothesis had been informed 
by studies suggesting that reward insensitivity constitutes a key component of apathy (36). There is debate on the conceptual stability of behavioral symptoms of apathy, which could help explain our results. For example, Levy and Dubois (17) suggest a replacement of the term behavioral apathy with the concept of an "auto-activation deficit," with reference to difficulties in activating thoughts or initiating motor programs necessary to complete an activity. Taken in this context, the IGT would not be a conceptually or a theoretically sound correlate of this dimension of apathy. Furthermore, the somatic marker hypothesis (33) that derives from research on performance on the task suggests that efficient performance requires the engagement of affective pre-biasing and tagging signals that aid the selection of adaptive behavioral choices (33). It is probably more reasonable to expect a relationship between impaired IGT performance and affective apathy symptoms. In line with this argument, Levy and Dubois (17) suggest that affective apathy may reflect an inability to associate those pre-biasing affective signals with ongoing and forthcoming behaviors.

\section{CONCLUSION}

Results from this study suggest that the three domains of apathy might have distinct neurocognitive correlates whose association with apathy may get masked by treating apathy as a unitary syndrome. Fractionating apathy symptoms into affective, cognitive, and behavioral sub-dimensions may be a useful approach to understand apathy and may also have greater utility in research and clinical practice. This approach also takes into account the fact that processes that direct and sustain human motivated behavior are broad; ranging from those that process rewards and punishments, those that are engaged in planning and executive control, to those that initiate motor sequences or sequences of thought. Deficits in any of these processes can disrupt goal directed behavior and manifest as an apathetic state. As noted by Levy and Czernecki (2), the physiopathology of apathy may depend on which specific process is disrupted during the execution of goal directed behavior.

Several limitations of this study should, however, be mentioned. First, the sample of patients was small, and this limited the power of the study. A bigger sample size is needed to strengthen the relationships between the study variables, especially where the results neared significance. For this reason, the near significant results can only be interpreted with caution. Furthermore, the multiple comparisons made on the same sets of data increased the chances of making family-wise type 1 errors. In some cases, the theoretical foundation for picking up predictors for the hierarchical regression models was not robust enough. This is particularly the case in relation to the association of behavioral apathy symptoms with IGT performance. There is still a lot of gray areas around the conceptualization and definition of apathy, which makes it difficult to come up with a solid theoretical framework for research. Future studies may also investigate symptom-lesion relationships or use brain imaging techniques to investigate the neural substrates of the individual sub-domains of apathy. The study focus can also be sharpened a bit further. For instance, future studies may investigate how these sub-domains of apathy relate to deficits in recognizing specific emotions, or relate to specific sub-domains of depressive symptoms.

\section{AUTHOR CONTRIBUTIONS}

Progress Njomboro was involved in the conception and design of the study, collected and analyzed the data, and also did the writeup. Shoumitro Deb was involved in the conception and design of the study.

\section{ACKNOWLEDGMENTS}

The research was supported by grants from the University of Birmingham, the University of Cape Town, the Birmingham and Solihull Mental Health Foundation NHS Trust, the Medical Research Council, the Stroke Association, and The Canon Collins Educational Trust for Southern Africa.

\section{REFERENCES}

1. Arnould A, Rochat L, Azouvi P, Van der Linden MA. Multidimensional approach to apathy after traumatic brain injury. Neuropsychol Rev (2013) 23:210-33. doi:10.1007/s11065-013-9236-3

2. Levy R, Czernecki V. Apathy and the basal ganglia. J Neurol (2006) 253(7):vii54-61. doi:10.1007/s00415-006-7012-5

3. Starkstein SE, Leentjens AF. The nosological position of apathy in clinical practice. J Neurol Neurosurg Psychiatry (2008) 79:1088-92. doi:10.1136/jnnp.2007. 136895

4. Marin RS, Wilkosz PA. Disorders of diminished motivation. J Head Trauma Rehabil (2005) 20:377-88. doi:10.1097/00001199-200507000-00009

5. Robert PH, Clairet S, Benoit M, Koutaich J, Bertogliati C, Tible O, et al. The apathy inventory: assessment of apathy and awareness in Alzheimer's disease, Parkinson's disease and mild cognitive impairment. Int J Geriatr Psychiatry (2002) 17:1099-105. doi:10.1002/gps.755

6. Kant R, Duffy JD, Pivovarnik A. Prevalence of apathy following head injury. Brain Inj (1998) 12:87-92. doi:10.1080/026990598122908

7. Caeiro L, Ferro JM, Costa J. Apathy secondary to stroke: a systematic review and meta-analysis. Cerebrovasc Dis (2013) 35:23-39. doi:10.1159/000346076

8. Lane-Brown AT, Tate RL. Apathy after acquired brain impairment: a systematic review of non-pharmacological interventions. Neuropsychol Rehabil (2009) 19:481-516. doi:10.1080/09602010902949207

9. Andersson S, Krogstad JM, Finset A. Apathy and depressed mood in acquired brain damage: relationship to lesion localization and psychophysiological reactivity. Psychol Med (1999) 29:447-56. doi:10.1017/S0033291798008046

10. Gray JM, Shepherd M, McKinlay WW. Negative symptoms in the traumatically brain-injured during the first year post discharge, and their effect on rehabilitation status, work status and family burden. Clin Rehabil (1994) 8:188-97. doi:10.1080/09602010902949207

11. Hama S, Yamashita H, Shigenobu M, Watanabe A, Hiramoto K, Kurisu K, et al. Depression or apathy and functional recovery after stroke. Int J Geriatr Psychiatry (2007) 22:1046-51. doi:10.1002/gps.1866

12. Zahodne LB, Tremont G. Unique effects of apathy and depression signs on cognition and function in amnestic mild cognitive impairment. Int J Geriatr Psychiatry (2013) 28:50-6. doi:10.1002/gps.3789

13. Mazaux JM, Masson F, Levin HS, Alaoui P, Maurette P, Barat M. Long-term neuropsychological outcome and loss of social autonomy after traumatic brain injury. Arch Phys Med Rehabil (1997) 78:1316-20. doi:10.1016/S0003-9993(97) 90303-8

14. Prigatano GP. Personality disturbances associated with traumatic brain injury. J Consult Clin Psychol (1992) 60:360-8. doi:10.1037/0022-006X.60.3.360

15. Dujardin K, Sockeel P, Devos D, Delliaux M, Krystkowiak P, Destee A, et al. Characteristics of apathy in Parkinson's disease. Mov Disord (2007) 22:778-84. doi: $10.1002 / \mathrm{mds} .21316$

16. Shapiro ME, Mahoney JR, Peyser D, Zingman BS, Verghese J. Cognitive reserve protects against apathy in individuals with human immunodeficiency virus. Arch Clin Neuropsychol (2013) 29(1):110-20. doi:10.1093/arclin/act071

17. Levy R, Dubois B. Apathy and the functional anatomy of the prefrontal cortex-basal ganglia circuits. Cereb Cortex (2006) 16:916-28. doi:10.1093/ cercor/bhj043

18. Faerden A, Vaskinn A, Finset A, Agartz I, Barrett EA, Friis S, et al. Apathy is associated with executive functioning in first episode psychosis. BMC Psychiatry (2009) 9:1. doi:10.1186/1471-244X-9-1 
19. Willer B, Flaherty PM, Coallier S. Families living with acquired brain injury. In: Wood RL, McMillan TM, editors. Neurobehavioural Disability and Social Handicap Following Traumatic Brain Injury. New York, NY: Oxford University Press (2001). p. 47-63.

20. Marin RS. Apathy: a neuropsychiatric syndrome. J Neuropsychiatry Clin Neurosci (1991) 3(3):243-54.

21. Marin RS, Biedrzycki RC, Firinciogullari S. Reliability and validity of the Apathy Evaluation Scale. Psychiatry Res (1991) 38:143-62. doi:10.1016/0165-1781(91) 90040-V

22. Marin RS, Firinciogullari S, Biedrzycki RC. The sources of convergence between measures of apathy and depression. J Affect Disord (1993) 28:117-24. doi:10. 1016/0165-0327(93)90072-R

23. Stanton BR, Leigh PN, Howard RJ, Barker GJ, Brown RG. Behavioural and emotional symptoms of apathy are associated with distinct patterns of brain atrophy in neurodegenerative disorders. J Neurol (2013) 260(10):2481-90. doi:10.1007/s00415-013-6989-9

24. Chow TW, Binns MA, Cummings JL, Lam I, Black SE, Miller BL, et al. Apathy symptom profile and behavioral associations in frontotemporal dementia vs dementia of Alzheimer type. Arch Neurol (2009) 66:888. doi:10.1001/archneurol. 2009.92

25. Sultzer DL, Leskin LP, Jacobs ZM, Melrose RJ, Harwood DG, Narvaez TA, et al. Cognitive, behavioral, and emotional domains of apathy in Alzheimer's disease: clinical and neurobiological features. Am J Geriatr Psychiatry (2013) 21:S144-5. doi:10.1016/j.jagp.2012.12.190

26. Stuss DT, van Reekum R, Murphy KJ. Differentiation of states and causes of apathy. In: Borod ED, editor. The Neuropsychology of Emotion. New York: Oxford University Press (2000). p. 340-63.

27. Knutson KM, Monte OD, Raymont V, Wassermann EM, Krueger F, Grafman J. Neural correlates of apathy revealed by lesion mapping in participants with traumatic brain injuries. Hum Brain Mapp (2013) 35(3):943-53. doi:10.1002/hbm.22225

28. Humphreys GW, Bickerton WL, Samson D, Riddoch MJ. The Birmingham Cognitive Screen (BCoS). London: Psychology Press (2012).

29. Beck AT, Steer RA, Brown GK. BDI-II, Beck Depression Inventory: Manual. 2nd ed. Boston: Harcourt Brace (1996).

30. Young A, Perret D, Calder A, Sprengelmeyer R, Ekman P. Facial Expression of Emotion: Stimuli and Tests (FEEST). Suffolk: Thames Valley Test Company (2002).

31. Burgess PW, Shallice T. The Hayling and Brixton Tests. Thurston: Thames Valley Test Company (1997).

32. van den Berg E, Nys GM, Brands AM, Ruis C, van Zandvoort MJ, Kessels RP. The Brixton Spatial Anticipation Test as a test for executive function: validity in patient groups and norms for older adult. J Int Neuropsychol Soc (2009) 15:695-703. doi:10.1017/S1355617709990269

33. Bechara A, Damasio AR, Damasio H, Anderson SW. Insensitivity to future consequences following damage to human prefrontal cortex. Cognition (1994) 50:7-15. doi:10.1016/0010-0277(94)90018-3

34. Skidmore FM, Yang M, Baxter L, Von Deneen K, Collingwood J, He G, et al. Apathy, depression, and motor symptoms have distinct and separable resting activity patterns in idiopathic Parkinson disease. Neuroimage (2011) 81:484-95. doi:10.1016/j.neuroimage.2011.07.012
35. Marin RS, Firinciogullari S, Biedrzycki RC. Group differences in the relationship between apathy and depression. J Nerv Ment Dis (1994) 182(4):235-9. doi:10.1097/00005053-199404000-00008

36. Rochat L, Van der Linden M, Renaud O, Epiney JB, Michel P, Sztajzel R, et al. Poor reward sensitivity and apathy after stroke: implication of basal ganglia. Neurology (2013) 81:1674-80. doi:10.1212/01.wnl.0000435290.49598.1d

37. Starkstein SE, Merello M, Jorge R, Brockman S, Bruce D, Power B. The syndromal validity and nosological position of apathy in Parkinson's disease. Mov Disord (2009) 24:1211-6. doi:10.1002/mds.22577

38. Levy ML, Cummings JL, Fairbanks LA, Masterman D, Miller BL, Craig AH, et al. Apathy is not depression. J Neuropsychiatry Clin Neurosci (1998) 10:314-9.

39. Martínez-Corral M, Pagonabarraga J, Llebaria G, Pascual-Sedano B, GarcíaSánchez C, Gironell A, et al. Facial emotion recognition impairment in patients with Parkinson's disease and isolated apathy. Parkinsons Dis (2010) 2010:930627. doi: $10.4061 / 2010 / 930627$

40. Albuquerque L, Coelho M, Martins M, Guedes LC, Rosa MM, Ferreira JJ, et al. STN-DBS does not change emotion recognition in advanced Parkinson's disease. Parkinsonism Relat Disord (2014) 20(2):166-9. doi:10.1016/j.parkreldis. 2013.10.010

41. Drapier D, Péron J, Leray E, Sauleau P, Biseul I, Drapier S, et al. Emotion recognition impairment and apathy after subthalamic nucleus stimulation in Parkinson's disease have separate neural substrates. Neuropsychologia (2008) 46:2796-801. doi:10.1016/j.neuropsychologia.2008.05.006

42. Reijnders JS, Scholtissen B, Weber WE, Aalten P, Verhey FR, Leentjens AF. Neuroanatomical correlates of apathy in Parkinson's disease: a magnetic resonance imaging study using voxel-based morphometry. Mov Disord (2010) 25:2318-25. doi: $10.1002 / \mathrm{mds} .23268$

43. Varanese S, Perfetti B, Ghilardi MF, Di Rocco A. Apathy, but not depression, reflects inefficient cognitive strategies in Parkinson's disease. PLoS One (2011) 6:e17846. doi:10.1371/journal.pone.0017846

44. Poletti M, De Rosa A, Bonuccelli U. Affective symptoms and cognitive functions in Parkinson's disease. J Neurol Sci (2012) 317:97-102. doi:10.1016/j.jns.2012. 02.022

Conflict of Interest Statement: The authors declare that the research was conducted in the absence of any commercial or financial relationships that could be construed as a potential conflict of interest.

Received: 13 January 2014; accepted: 01 May 2014; published online: 19 May 2014. Citation: Njomboro P and Deb S (2014) Distinct neuropsychological correlates of cognitive, behavioral, and affective apathy sub-domains in acquired brain injury. Front. Neurol. 5:73. doi: 10.3389/fneur.2014.00073

This article was submitted to Neurotrauma, a section of the journal Frontiers in Neurology.

Copyright (C) 2014 Njomboro and Deb. This is an open-access article distributed under the terms of the Creative Commons Attribution License (CC BY). The use, distribution or reproduction in other forums is permitted, provided the original author (s) or licensor are credited and that the original publication in this journal is cited, in accordance with accepted academic practice. No use, distribution or reproduction is permitted which does not comply with these terms. 